\title{
EVALUATION OF THE BALNEABILITY CONDITIONS OF THE URUBUÍ CORREDEIRA, IN THE MUNICIPALITY OF PRESIDENTE FIGUEIREDO - AMAZONAS
}

\section{${ }^{*}$ Danilo Gabriel Ferreira Salvador, ${ }^{1}$ William Saraiva Passos, ${ }^{1}$ Frank Henrique Santos Fontineles, ${ }^{1}$ Lívia da Silva Oliveira and ${ }^{2}$ David Barbosa de Alencar}

${ }^{1}$ Academic Department, University Center FAMETRO, Amazon-Brazil

2Institute of Technology and Education Galileo of Amazon (ITEGAM), Brazil

\section{ARTICLE INFO}

\section{Article History:}

Received $09^{\text {th }}$ February, 2020

Received in revised form

$11^{\text {th }}$ March, 2020

Accepted $16^{\text {th }}$ April, 2020

Published online $25^{\text {th }}$ May, 2020

\section{Key Words:}

Bathing; Water quality;

Fecal coliforms; Thermotolerant.

*Corresponding author: Danilo Gabriel

Ferreira Salvador,

\begin{abstract}
According to the environmental company of the state of São Paulo, bathing is associated with the use of water for the practice of recreational activity through primary contact, being understood as direct and long contact with water, with high risk of ingesting certain. For this purpose, it is essential to evaluate water quality, following some criteria, which are based on microorganisms indicating fecal contamination, established through monitoring and confrontation with preestablished standards. Thus, the general objective of this study is to evaluate the watering conditions of the vulture rapids, to define the quality and parameters of water for recreation use, in order to contribute to the environmental conservation and supervision of water resources. This research is a case study, conducted through bibliographic surveys, site visits, direct observation. The results obtained by laboratory analysis in the periods between September and October 2019, where all dates of points P1 and P2 presented concentrations below $250 \mathrm{CFU} / 100 \mathrm{~mL}$. According to CONAMA Resolution No. 274/2000, the results indicate that the bathing conditions for recreational use fall into the excellent category.
\end{abstract}

Copyright (C) 2020, Danilo Gabriel Ferreira Salvador et al. This is an open access article distributed under the Creative Commons Attribution License, which permits unrestricted use, distribution, and reproduction in any medium, provided the original work is properly cited.

Citation: Danilo Gabriel Ferreira Salvador, William Saraiva Passos, Frank Henrique Santos Fontineles, Livia da Silva Oliveira and David Barbosa de Alencar. "Evaluation of the balneability conditions of the urubuí corredeira, in the municipality of presidente figueiredo - amazonas", International Journal of Development Research, 10, (05), 35566-35571.

\section{INTRODUCTION}

O aumento da população mundial e a constante intervenção do homem no meio ambiente estão alterando a cada dia a qualidade das águas superficiais e subterrâneas que recebem elevadas descargas poluidoras degradando cada vez mais os escassos recursos hídricos (Campos et al., 2015). Deste modo, a utilização das águas para a prática de atividades de lazer que envolva o contato primário com as mesmas, tem sido sistematicamente comprometida em diversos ambientes aquáticos em todo o Brasil (Azevedo et al., 2013). Hoje utilizamos água como nosso maior recurso natural, para o consumo, hidratação, higienização, recreação, para o cultivo de alimentos e criação de animais. Com isso é de extrema importância seu cuidado e sua qualidade. Há necessidade de se intensificar os estudos de suas águas e caracterizá-las sob o aspecto físico, químico e biológico. Para a conservação ambiental e proteção da natureza. O uso da água para recreação em ambientes naturais pode trazer uma série de perigos àqueles em contato direto com a água (WHO, 1999).
Sobretudo a exposição a microrganismos patogênicos eventualmente presentes no ambiente aquático. Tradicionalmente, a avaliação das condições de balneabilidade é feita pelo monitoramento da concentração de microrganismos indicadores fecais na água. No Brasil, a regulamentação que define os critérios de avaliação e classificação de balneabilidade dos corpos hídricos é a Resolução CONAMA ñ 274, de 2000 (Brasil, 2001).

De acordo com a Companhia Ambiental do Estado de São Paulo - (CETESB, 2015):

Balneabilidade está associada ao uso da água para a prática de atividade de recreação, através do contato primário, sendo compreendido como o contato direto e demorado com a água, com elevado risco de ingerir certa quantidade de água. Para este fim, é primordial que seja avaliada a qualidade da água, seguindo alguns critérios. Esses critérios estão fundamentados em microrganismos indicadores de contaminação fecal, estabelecidos através de monitoramento e confrontamento com os padrões preestabelecidos. Assim, pode-se identificar se as 
condições de balneabilidade são favoráveis ou não. A análise da balneabilidade consiste basicamente, na avaliação da qualidade das águas para fins de recreação de contato primário, através dos indicadores microbiológicos. O Conselho Nacional do Meio Ambiente - CONAMA (2000) define que a recreação de contato primário está associada com o contato direto do usuário como curso de água, através da realização de práticas de mergulho, natação e esqui aquático, em que se manifesta a possibilidade de engolir certa quantidade de água. Segundo Lopes (2010), a utilização dos recursos hídricos para fins de recreação, tem se expandido e adquirido importância social e econômica ao longo dos últimos anos. Isso se deve basicamente à busca pelo desenvolvimento da prática recreativa aliada ao contato com o meio natural, de modo a confrontar como modo de vida na zona urbana. Dentre estas atividades, podem-se destacar as práticas de recreação de contato primário em cachoeiras, praias fluviais e reservatórios. Estes balneários naturais constituem intensos atrativos para as pessoas, intensificam o turismo e o ecoturismo, transformando-se em fontes econômicas de desenvolvimento sustentável. De acordo com a Organização Mundial da Saúde (OMS, 2003) cerca de $80 \%$ de todas as doenças que acometem os países em desenvolvimento provêm de água de má qualidade. Há muitas doenças de veiculação hídrica que ocasionam elevada taxa de mortalidade em indivíduos com baixa resistência imunológica.

Sendo muitas das vezes causados pela presença de Coliformes fecais (termo tolerantes) segundo o CONAMA 274/2000 define como bactérias pertencentes ao grupo dos coliformes totais caracterizadas pela presença da enzima $\beta$-galactosidade e pela capacidade de fermentar a lactose com produção de gás em 24 horas à temperatura de $44-45^{\circ} \mathrm{C}$ em meios contendo sais biliares ou outros agentes tenso-ativos com propriedades inibidoras semelhantes. Além de presentes em fezes humanas e de animais podem, também, ser encontradas em solos, plantas ou quaisquer efluentes contendo matéria orgânica. Segundo (Carvalho et al., 2017), o controle da poluição do recurso hídrico e o monitoramento intensivo da qualidade da água são mecanismos preponderantes na proteção da saúde dos usuários, na promoção do equilíbrio ecológico do meio ambiente e na garantia de melhorias na qualidade de vida e bem estar da comunidade. A região hidrográfica do Município de Presidente Figueiredo apresenta algumas demandas associadas aos usos múltiplos da água, com destaque para o uso na irrigação, além dos usos para dessedentação animal, locomoção via barcos, pesca turística e recreação. Considerando a necessidade de ser avaliada a qualidade das águas, em relação aos níveis estabelecidos para a balneabilidade, de forma a assegurar as condições necessárias à recreação de contato primário. $O$ tema balneabilidade apresenta uma enorme importância social, pois possui uma relação direta com os problemas de saúde pública e a degradação do meio ambiente (Andrade, et al. 2012). $\mathrm{O}$ objetivo geral do estudo é avaliar as condições de balneabilidade da Corredeira do Urubuí, para definir a qualidade e os parâmetros da água para uso da recreação, a fim de contribuir com a conservação ambiental e fiscalização dos recursos hídricos. Tendo como objetivos específicos: IIdentificar o parâmetro microbiológico encontrado no corpo hídrico; II- Analisar a qualidade da água em termos dos parâmetros de balneabilidade em dois pontos na corredeira do Urubuí e III- Comparar o parâmetro microbiológico com a Resolução CONAMA no ${ }^{\circ}$ 274/2000.

\section{MATERIAL E MÉTODOS}

Esta pesquisa utilizou como método o estudo de caso. Conforme Yin (2001) o estudo de caso é uma estratégia de pesquisa que compreende um método que abrange tudo em abordagens específicas de coletas e análise de dados. Esse estudo contribui para compreendermos melhor os fenômenos individuais, os processos organizacionais e políticos da sociedade. É uma ferramenta utilizada para entendermos a forma e os motivos que levaram a determinada decisão.

Área de Estudo: A pesquisa foi realizada na corredeira do Urubuí, localizado no município de Presidente Figueiredo, também conhecido como a "Terra das Cachoeiras", situado no noroeste do Estado do Amazonas, cerca de $110 \mathrm{~km}$ distante de Manaus, através da rodovia BR 174, Compreende uma área de $25.422,235 \mathrm{Km} 2$ e sua geologia, geomorfologia e as condições geográficas permitiram à formação de inúmeras corredeiras, cachoeiras e cavernas que, em conjunto com a exuberante floresta tropical equatorial nativa, conferem à região belezas naturais atrativas ao turismo.

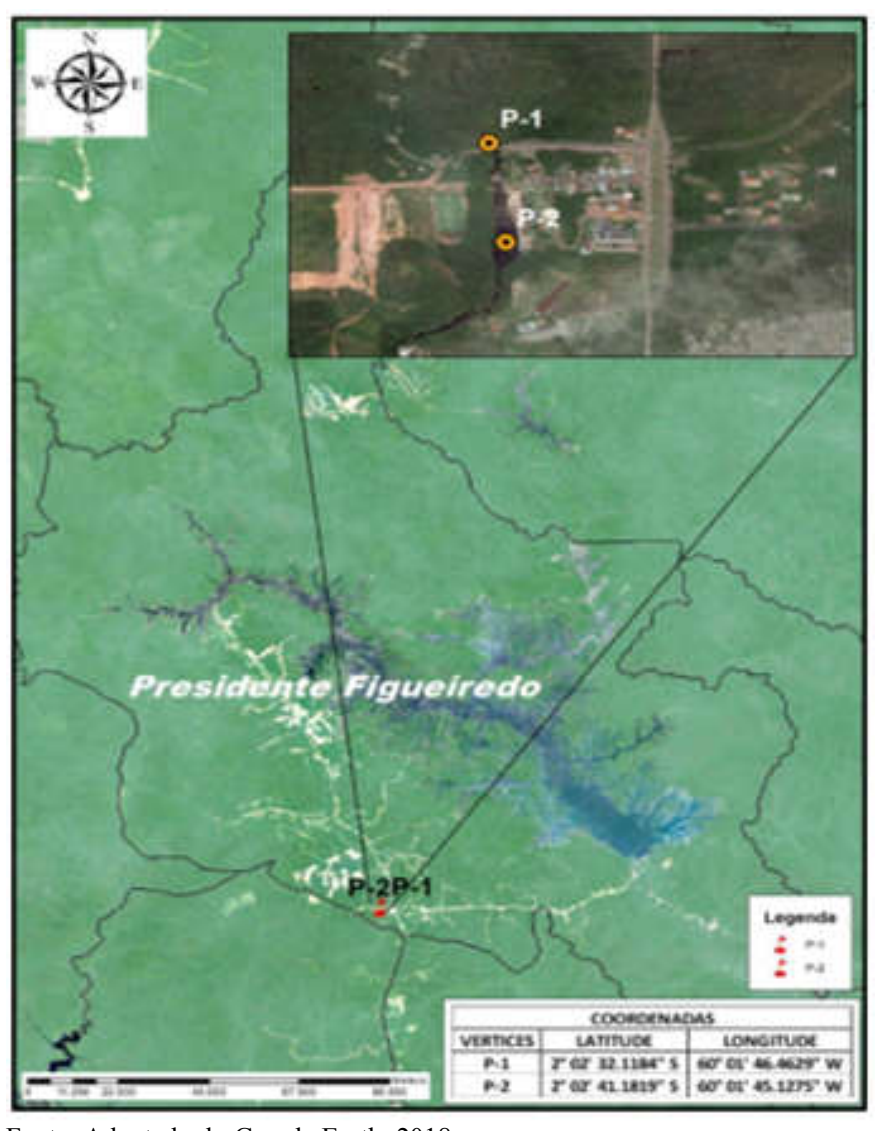

Fonte: Adaptado do Google Earth, 2018.

Fig. 1. Delimitações dos pontos amostrais, da Corredeira do Urubuí

\section{Coleta de Dados}

Para o desenvolvimento da pesquisa, foram adotados os seguintes procedimentos:

a) Levantamento bibliográfico: Nesta etapa foi realizado um levantamento bibliográfico através de literatura em artigos científicos, portarias, CONAMA e leis a respeito do assunto abordado, para então elaborar o método mais eficaz para a realização desse artigo. 
b) Visitas in loco e observação direta: Foi realizado visitas in loco entre os meses de junho/julho e no mês de setembro/outubro aos locais de coleta das amostras de água, conforme mostrado no quadro 1. Segundo Lakatos e Marconi (1992), a observação direta intensiva é um tipo de atividade que "[...] utiliza os sentidos na obtenção de determinados aspectos da realidade. Não consiste apenas em ver e ouvir, mas também examinar fatos ou fenômenos que se deseja estudar".

c) Registros fotográficos: Utilizando uma câmera de celular Moto G6 play, foi registrado no local todo o processo da coleta dos pontos escolhidos, para o levantamento de registros de informações.

d) Coletas de amostras in loco: Através do auxílio do aplicativo Google Earth foi determinado às coordenadas de dois pontos de coleta P1 e P2, no trecho da corredeira do Urubuí, com uma distância de 300 metros entre si. A área da recreação na corredeira possui aproximadamente 400 metros de extensão. Os pontos foram determinados em função da frequência de visitantes naquela área.

O ponto 1 (P1), Figura 2, é o primeiro trecho onde foi coletada a amostra, este situa-se a montante da corredeira e antecede a ponte que atravessa a corredeira, cujo a mesma é uma área menos frequenta pelos banhistas. $\mathrm{O}$ ponto $2(\mathrm{P} 2)$, figura 3 , foi realizado a coleta da segunda amostra e situa-se na parte a jusante a corredeira e é a área mais frequentada pelos banhistas.

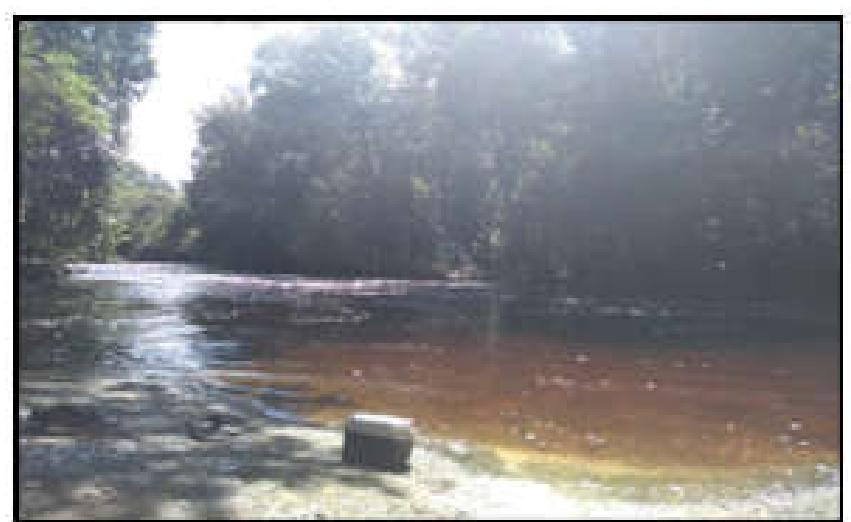

Fonte: Os Autores, (2020)

Fig. 2. Ponto 1

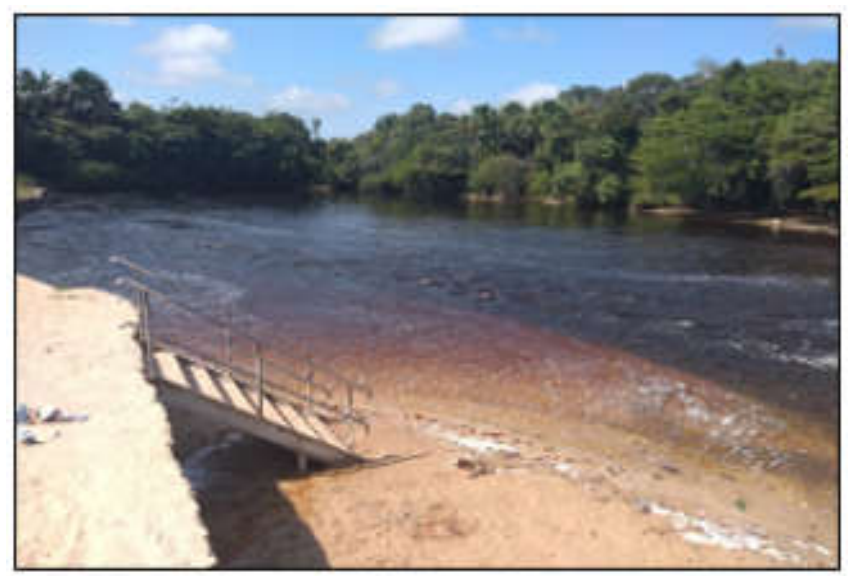

Fonte: Os Autores, (2020)

Fig. 3. Ponto 2
A Resolução CONAMA 274/2000 em seu Art. $n^{\circ}$ 5, explica que, a amostragem será feita, preferencialmente, nos dias de maior afluência do público às praias ou balneários, a critério do órgão de controle ambiental competente. E no Art. $n^{\circ} 6$, explica que, os resultados dos exames poderão, também, abranger períodos menores que cinco semanas, desde que cada um desses períodos seja especificado e tenham sido colhidas e examinadas, pelo menos, cinco amostras durante o tempo mencionado, com intervalo mínimo de 24 horas entre as amostragens.

Tabela 1. Períodos das coletas realizadas entre os meses de junho/julho que representa o período chuvoso e setembro/outubro que representa o período da Vazante

\begin{tabular}{|c|c|c|c|}
\hline \multicolumn{2}{|c|}{ junho/julho* } & \multicolumn{2}{c|}{ setembro/outubro } \\
\hline $\begin{array}{c}\text { Datas de } \\
\text { Coletas }\end{array}$ & $\begin{array}{c}\text { Pontos } \\
\text { Coletados }\end{array}$ & $\begin{array}{c}\text { Datas de } \\
\text { Coletas }\end{array}$ & $\begin{array}{c}\text { Pontos } \\
\text { Coletados }\end{array}$ \\
\hline $17 / 06 / 2019$ & 1 e 2 & $26 / 09 / 2019$ & 1 e 2 \\
\hline $24 / 06 / 2019$ & 1 e 2 & $30 / 09 / 2019$ & 1 e 2 \\
\hline $01 / 07 / 2019$ & 1 e 2 & $04 / 10 / 2019$ & 1 e 2 \\
\hline $08 / 07 / 2019$ & 1 e 2 & $08 / 10 / 2019$ & 1 e 2 \\
\hline- & - & $11 / 10 / 2019$ & 1 e 2 \\
\hline
\end{tabular}

*Obs.: As amostras do período de junho/julho foram invalidadas devido a um erro que ocorreu no laboratório, consequentemente, os dados obtidos não eram precisos com as informações corretas. Sendo assim, somente serão apresentados os dados dos períodos de setembro/outubro.

As coletas foram repetidas sempre nas mesmas coordenadas e conforme o quadro acima, respeitando as determinações da Resolução CONAMA no $274 / 2000$, para retiradas das amostras foram coletados aproximadamente na isóbata de um metro de profundidade, que representa a região mais utilizada na recreação de contato primário. Empregando o método de amostragem preconizado pelo Guia Nacional de Coleta de Água (2011), a água foi coletada a uma profundidade de $20 \mathrm{~cm}$ abaixo da superfície da lâmina d'água utilizando recipientes esterilizados e identificados, com capacidade para $100 \mathrm{ml}$, quantidade suficiente para a realização da análise.

Após a coleta, os recipientes, com capacidade para $100 \mathrm{ml}$, foram lacrados e preservados em caixas isotérmicos devidamente refrigerados para evitar elevado crescimento dos microrganismos até a chegada ao laboratório, onde se procederam as análises para determinação da concentração de coliformes fecais (termotolerantes).

Análise dos Dados: Conforme a metodologia empregada pelo CONAMA 274/2000 que traz em seu Art. n ${ }^{\circ}$, os métodos de amostragem e análise das águas devem ser os especificados nas seguintes normas aprovadas: I- Pelo Instituto Nacional de Metrologia, Normatização e Qualidade Industrial-INMETRO ou, na ausência destas, II- A de Standard Methods for the Examination of Water and Wastewater-APHA-AWWAWPCF, última edição. (Métodos Padrão para o Exame de Água e efluentes. $22^{\circ}$ Edição APHA, WEF, AWWA e ICR. Manual do Laboratório Microbiano de APHA, WEF, AWWA E ICR). Após as coletas realizadas, as amostras foram analisadas no laboratório onde a avaliação da qualidade da água para balneabilidade foi baseada na segunda metodologia empregada pelo CONAMA (2000). De acordo com a Resolução CONAMA 274/2000 as águas doces, salobras e salinas destinadas à balneabilidade (recreação de contato primário) tem sua condição avaliada nas categorias própria e 
imprópria. Os requisitos para classificação estão reproduzidos na tabela 2, abaixo.

Tabela 2. Critérios para classificação das condições de balneabilidade

\begin{tabular}{|c|c|c|}
\hline CLASS. & $\begin{array}{l}\text { CATEGOR } \\
\text { IA }\end{array}$ & $\begin{array}{l}\text { LIMITE DE COLIFORMES FECAIS } \\
\text { /TERMOTOLERANTES }\end{array}$ \\
\hline \multirow[t]{3}{*}{ PRÓPRIA } & Excelente & $\begin{array}{l}\text { Máximo de } 250 \text { em } 80 \% \text { ou mais das } \\
\text { amostras }\end{array}$ \\
\hline & Muito Boa & $\begin{array}{l}\text { Máximo de } 500 \text { em } 80 \% \text { ou mais das } \\
\text { amostras }\end{array}$ \\
\hline & Satisfatória & $\begin{array}{l}\text { Máximo de } 1000 \mathrm{em} 80 \% \text { ou mais das } \\
\text { amostras }\end{array}$ \\
\hline IMPRÓPRIA & Imprópria & $\begin{array}{l}\text { Não atendimento aos critérios } \\
\text { estabelecidos para as águas próprias** }\end{array}$ \\
\hline
\end{tabular}

**Ou é considerado impróprio, quando o valor da última amostra for $>2500 \mathrm{UFC} / 100 \mathrm{~mL}$ (termotolerantes). Caso o local da recreação se torne imprópria para o uso, será interditada por órgão municipal, estadual ou federal.

\section{RESULTADOS E DISCUSSÃO}

Coliformes Fecais (CF): Os resultados obtidos através das análises de dados entre os períodos de setembro e outubro de 2019, todas as datas dos pontos P1 e P2 apresentaram concentrações abaixo de $250 \mathrm{UFC} / 100 \mathrm{~mL}$. Conforme a resolução do CONAMA n²74/2000, os resultados indicam que as condições de balneabilidade para uso de recreação se encaixam na categoria excelente. Todas as coletadas feitas durante esta pesquisa apresentaram resultados $<10$ UFC/100mL conforme o (Limite de Quantificação estabelecido pelo laboratório como valor mínimo de CF detectados), exceto as coletas de P1 e P2 do dia 27/09/2019, cujo os mesmo apresentaram resultados $>10 \mathrm{UFC} / 100 \mathrm{~mL}$, entretanto não variando na classificação de excelente, conforme a Figura 4 a seguir.

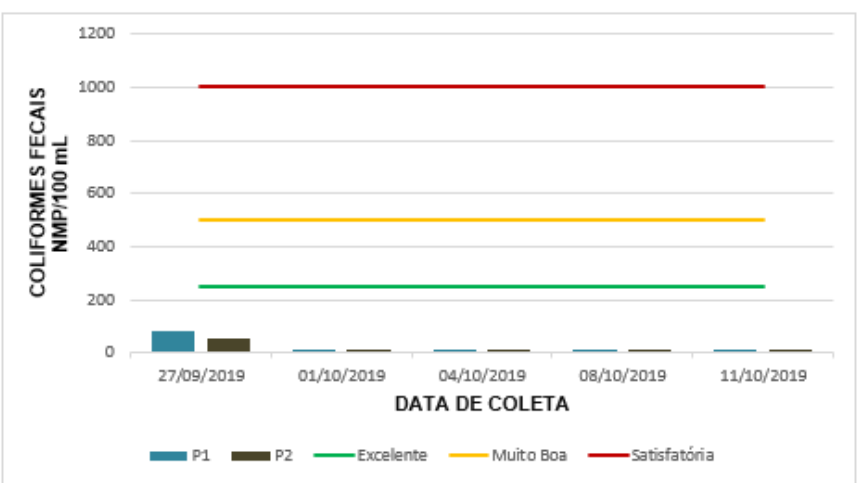

Fonte: Os Autores, (2020)

Fig. 4. Resultados das análises da corredeira do Urubuí

Nas análises de balneabilidade feitas por Dourado et al., (2015), as águas da corredeira do Urubuí no período de agosto e novembro de 2014 (período de Vazante), os resultados foram menores que $1000 \mathrm{UFC} / 100 \mathrm{~mL}$ e também foram classificadas como excelente. Entretanto, no período entre março e maio de 2015 (período Chuvoso), houve uma variação em suas análises, onde os resultados variaram de $250 \mathrm{UFC} / 100 \mathrm{~mL}$ e uma de 1000 C.F $/ 100 \mathrm{ml}$, a partir da média feita pelo autor, exigido pelo CONAMA, o mesmo classificou que as análises estão na categoria muito boa. Os estudos de balneabilidade realizados por Arcos et al., (2009), na praia do Tupé localizada no município de Manaus - AM, para o período Chuvoso (setembro e outubro) de 2009, também apresentaram classificações como excelente, entretanto, Arcos (2009) analisou as águas da praia da Ponta Negra localizada no município de Manaus - AM e para o mesmo período foram classificadas como imprópria (ultrapassando os limites máximos estipulados pelo CONAMA). Essa diferença de aumento de concentração de Coliformes Fecais entre o período sazonal (Chuvoso e Vazante), pode ser associado ao mencionado por WHO (2003) e Souza et. al (2017), que a elevada concentração de bactérias identificada no período chuvoso possivelmente pode ser explicada pelo maior carregamento de substâncias fecais, através do aumento do escoamento superficial, provenientes de águas pluviais em áreas urbanas e rurais, e ainda de galerias pluviais e córregos, dessa maneira favorece a contaminação das águas, acarretando no aumento significativo da densidade de bactérias, comprometendo a qualidade das águas balneárias.

Já Van Asperen et al.,(1995) e CETESB (2003). Outro importante fator a ser considerado refere-se ao aumento na concentração de banhistas durante os períodos da vazante, o qual atrai maior quantidade de visitante, podendo ocorrer problemas de sobrecarga nos sistemas de coleta existentes, de forma que o excedente seja lançado nos córregos favorecendo o aumento da carga de patógenos na água. Além disso, as maiores temperaturas da água observadas neste período podem favorecer a proliferação de certos tipos de patógenos comprometendo a balneabilidade. Conforme as citações dos autores sobre a justificativa de maior concentração entre o período sazonal (Chuvoso e Vazante) neste presente estudo não se pode afirmar que tal período do ano houve uma maior concentração de coliformes fecais devido às análises realizadas na corredeira do Urubuí no período de estiagem foram invalidada como dito na $*$ obs. da tabela 1 , sendo assim, foram somente apresentados os dados do período de vazante.

Visita in loco e Registro fotográfico: A partir das visitas in loco, observam-se atividades antrópicas, como a presença de estruturas de lazer para comércio e alimentação de moradores e visitantes da cidade de Presidente Figueiredo. Dentre as atividades estabelecidas ao redor da corredeira, verifica-se a presença de 20 boxes de alimentação, cujas mesmas acomodam mesas e cadeiras para os banhistas, observa-se também o descarte incorreto de resíduos provenientes destes comércios, como por exemplo, os efluentes das cozinhas, que são lançados diretamente em caneletas e tubulaçõespresentes nas edificações, cuja destinação final é a parte mais baixa da corredeira. Foram feitos registros fotográficos das seguintes conjunturas conforme as imagens a seguir:

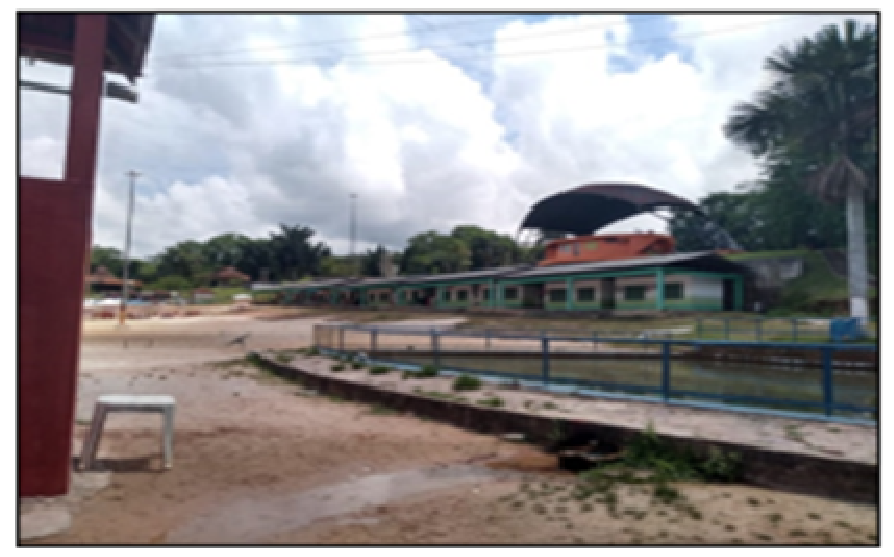

Fonte: Os Autores, (2020)

Fig. 5. Total de 20 boxes no entorno 


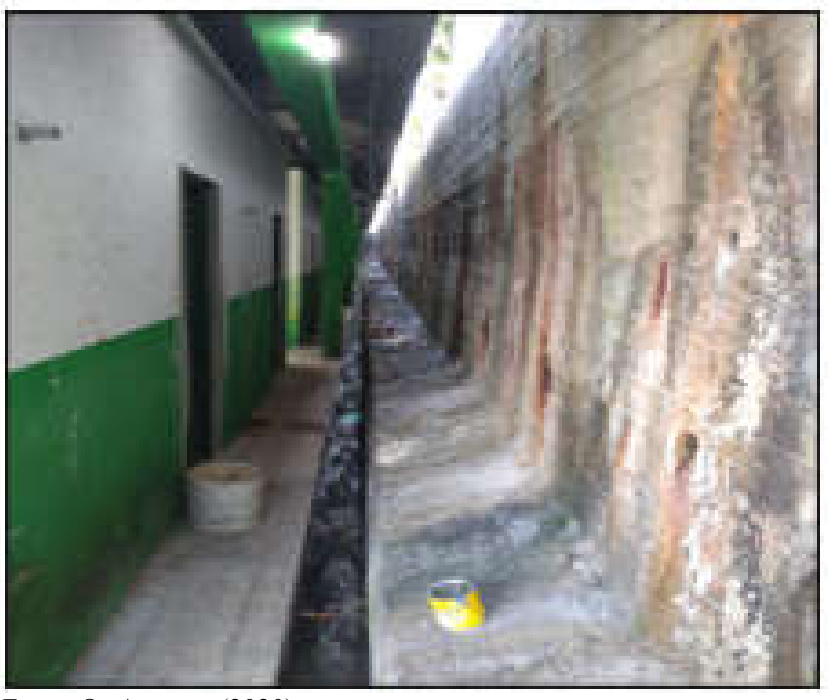

Fonte: Os Autores, (2020).

Fig. 6. Efluentes saindo dos boxes

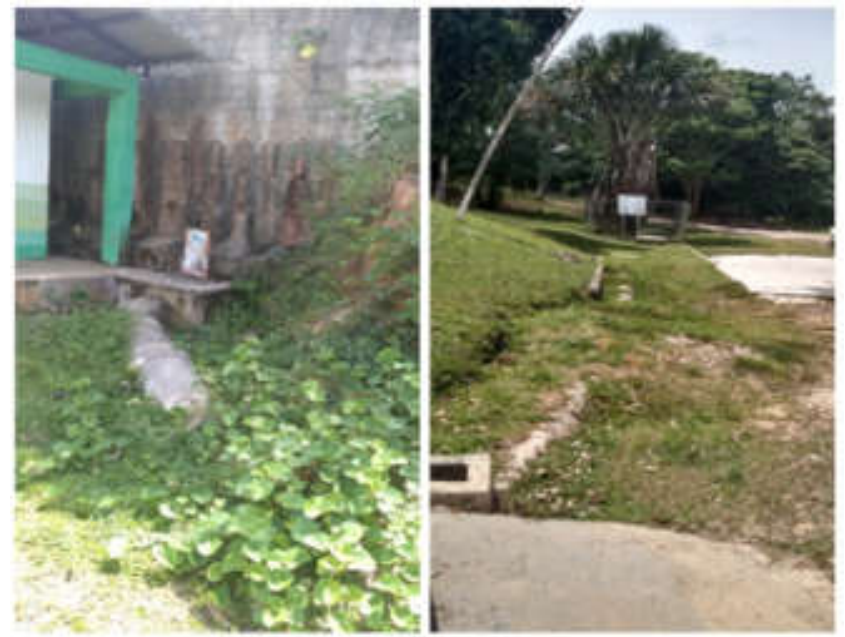

Fonte: Os Autores, (2020).

Fig. 7. Caneletas e tubulações presentes

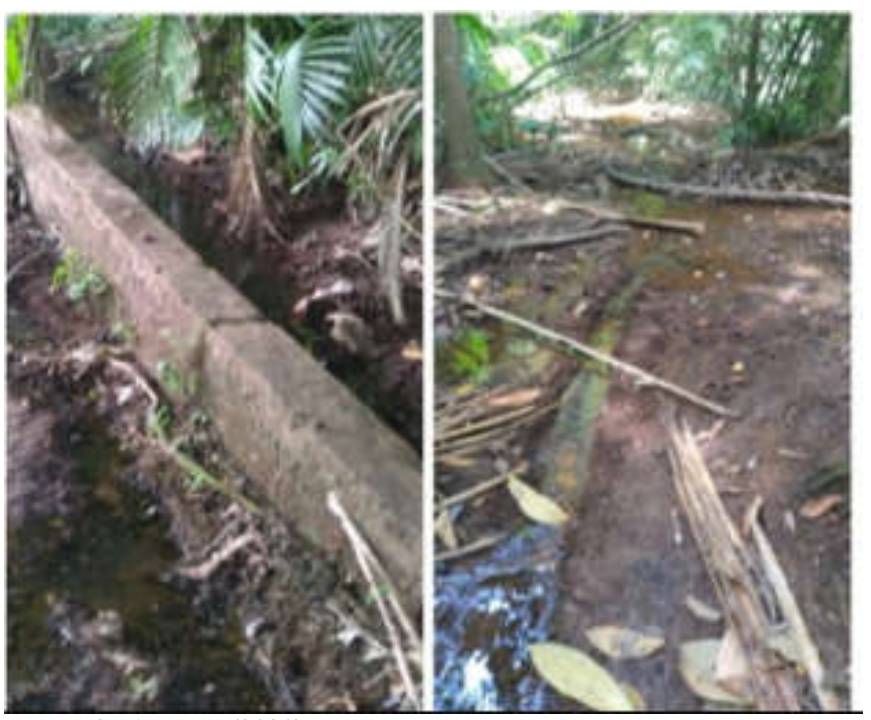

Fonte: Os Autores, (2020).

Fig. 8. Descarte do efluente

Outro ponto observado foi em relação à coloração da areia no local que apresentava uma coloração amarelada, onde em algumas partes saiam um liquido oleoso, conforme mostrado na Figura 10. Não se sabe o motivo por estar assim, mas recomenda-se aos órgãos ambientais a avaliação das condições parasitológicas e microbiológicas da areia, para futuras padronizações. Conforme dito no Art. $8^{\circ}$ da resolução do Conama 274/200.

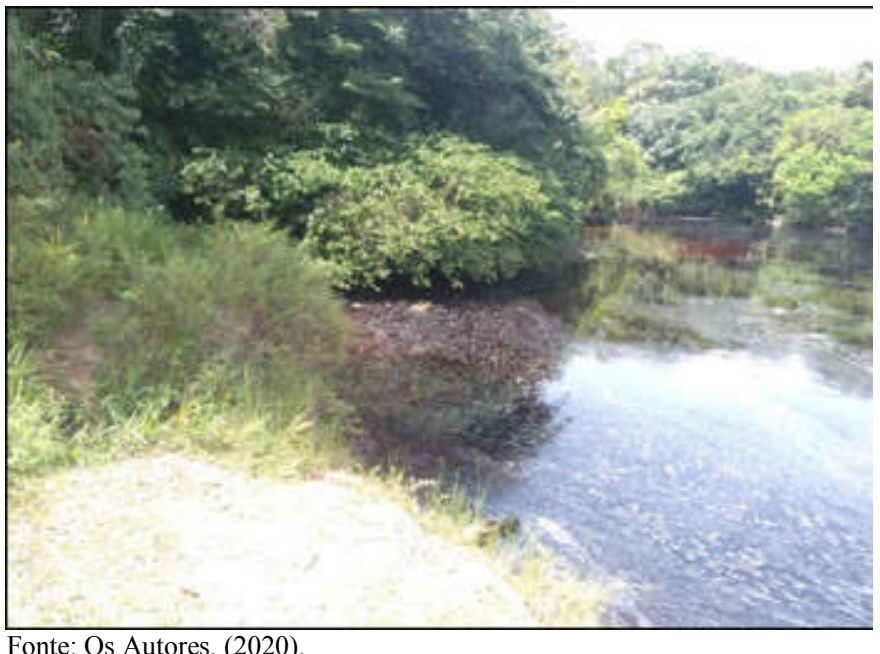

Fig. 9. Destinação final do efluente

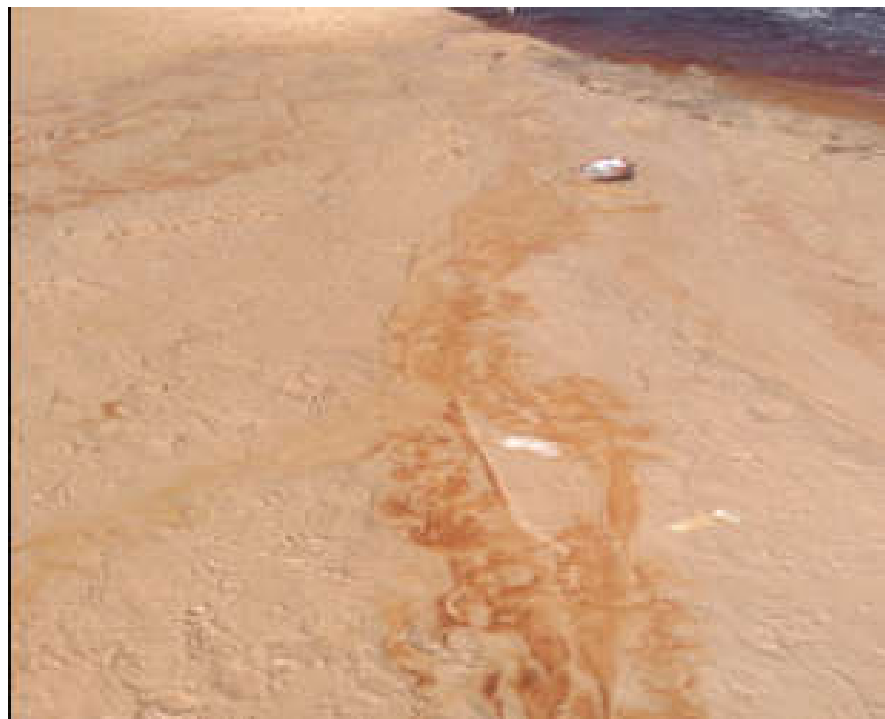

Fonte: Os Autores, (2020).

Fig. 10. Líquido oleoso presente na areia

Mediante a isso é de competência aos órgãos de controle ambiental realizar o monitoramento das condições de balneabilidade, divulgar as condições de balneabilidade das praias e dos balneários e a fiscalização para o cumprimento da legislação pertinente.

\section{Conclusão}

Os resultados aferidos a partir das análises microbiológicas das amostras de água coletadas na Corredeira do Urubu em Presidente Figueiredo - AM confirmaram a presença de coliformes fecais em todos os pontos de monitoramento, durante o período de estudo, entretanto ao comparar os resultados com os valores propostos pela Resolução $n^{\circ}$ 274/2000 do CONAMA para balneabilidade, foi possível classificar as águas quanta à balneabilidade, como águas próprias para utilização durante os meses de setembro e outubro, subdividida na categoria de "excelente". A avaliação dos parâmetros de balneabilidade das águas da Corredeira do Urubuí, no período de monitoramento, confirma que o local 
apresenta condições próprias para o uso da recreação de contato primário. No entanto, nas proximidades do local possuem boxes de alimentações, restaurantes, residências, secretarias e hospital. Mediante a isso, manter o controle da poluição do recurso hídrico e o monitoramento intensivo da qualidade da água é mecanismos preponderantes na proteção da saúde dos usuários, na promoção do equilíbrio ecológico do meio ambiente e na garantia de melhorias na qualidade de vida e bem estar da comunidade. Diante do contexto apresentado na pesquisa, para a melhoria da qualidade da água da corredeira, bem como o bem estar da população sugere-se: I- Estabelecer um programa de monitoramento da água, como prática adequada para oferecer maior segurança sanitária aos banhistas; II- Executar periodicamente limpeza das margens do rio e de resíduos no entorno, para evitar que sejam carreados para corpo hídrico durante o período de chuva; IIIEstimular a população a buscar informações sobre as condições de qualidade da água antes de utilizá-las na recreação e IV- Implantar dispositivos de informação (placas ou boletins) pelo poder público com indicação das condições da água, assim oferecer melhor orientação e segurança sanitária aos banhistas.

\section{REFERÊNCIA}

ARCOS, A. N.; CUNHA, H. B.; BRINGEL, S. R. B. Condições de balneabilidade eavaliação do índice da qualidade da água de três praias do rio Negro, Manaus AM. In: XVIII Jornada de Iniciação Científica. Anais. Manaus: PIBICCNPQ/FAPEAM/INPA, 2009, p. 558-562.

BRANDÃO, Carlos Jesus, et al. Guia nacional de coleta e preservação de amostras: água, sedimento, comunidadesaquáticase efluentes líquidos. São Paulo: CETESB, 2011.

CAMPOS, Jonas Silva; CUNHA, Helenilza Ferreira Albuquerque. Análise comparativa de parâmetros de balneabilidade em Fazendinha, Macapá-AP. Biota Amazônia (BioteAmazonie, Biota Amazônia, Amazonian Biota), v. 5, n. 4, p. 110-118, 2015.

CETESB - Companhia Ambiental Do Estado De São Paulo. Relatório da qualidade das praias litorâneas do estado de São Paulo 2014. São Paulo: CETESB, 2015.
CETESB, Companhia de Tecnologia de Saneamento. Ambiental. Relatório de qualidade das aguas interiores do estado de são paulo, 2003.

CONAMA - Conselho Nacional do Meio Ambiente. Resolução $n^{\circ} 274$, de 29 de novembro de 2000. Define os critérios de balneabilidade em águas brasileiras. Disponível em: $<$ http://www.mma.gov.br/port/conama/legiabre.cfm?codle gi $=272>$. Acesso em: 8 de janeiro de 2020 .

DA AZEVEDO LOPES, Frederico Wagner; MAGALHÃES JR, Antônio Pereira; VON SPERLING, Eduardo. Balneabilidade em águas doces no brasil: Riscos a saúde, limitações metodológicas e operacionais. Hygeia: Revista Brasileira de Geografia Médica e da Saúde, v. 9, n. 16, p. 28, 2013.

DOURADO, M. O. V. Avaliação dos coliformes nas águas das cachoeiras e corredeiras em presidente figueiredo/AM. Manaus: PIBIC/CNPQ/FAPEAM/INPA, 2015.

HIRAI, Fabio Muller; DO AMARAL PORTO, Monica Ferreira. O desenvolvimento de ferramentas de predição de balneabilidade baseadas em níveis de precipitaçãoEstudo de caso da praia de Cachoeira das Emas, SP. Engenharia Sanitária e Ambiental, 2017, 21.4.

LAKATOS, Maria Eva; MARCONI, M. de A. Metodologia do Trabalho Cientifico. São Paulo. Revista e Ampliada. Atlas, $1992.5 \mathrm{v}$.

LOPES, F. W. de A.; MAGALHÃES JR, A. P. M. Avaliação da qualidade das águas para recreação de contato primário na bacia do alto rio das velhas - MG. HYGEIA, Revista Brasileira de Geografia Médica e da Saúde, V.6, n. 11, 2010.

VAN ASPEREN, I.A. et al. Risk of otitis externa afterswimming in recreational fresh water lakescontaining Pseudomonas aeruginosa. BMJ. v.311, p.1407-1410,1995.

World Health Organization (WHO). Guidelines for safe recreational water environments - coastal and freshwaters. Genebra, 2003.

WORLD HEALTH ORGANIZATION - WHO. Health-based monitoring of recreational waters: the feasibility of a new approach (the "AnnapolisProtocol") Geneva. 50 p. (1999) (Protection of the HumanEnvironment: Water, Sanitation and Health Series). Disponível em: <Disponível em: http://www.who.int/water_sanitation_health/bathing/wsh9 901/en/ > . Acesso em: 8 de janeiro de 2020. 